\title{
TÁC ĐộNG CỦA MỤC TIÊU PHÁT TRIỂN \\ TRONG BÁO CÁO CHÍNH TRI TẠI ĐẠI HỘI 19 \\ ĐẢNG CộNG SẢN TRUNG QUỐC ĐẾN CHIINH SÁCH \\ ĐỐI NGOẠI ĐỐI VỚI VIẸTT NAM
}

\author{
Nguyễn Ngọc Anh* \\ Trung tâm Nghiên cưu Giáo dục Ngoại ngũu, Ngôn ngũ và Quốc tế học, \\ Trường Đại học Ngoại ngũu, ĐHQGHN, Phạm Văn Đồng, Cầu Giấy, Hà Nội, Việt Nam
}

Nhận bài ngày 28 tháng 10 năm 2017

Chỉnh sửa ngày 16 tháng 01 năm 2018; Chấp nhận đăng ngày 31 tháng 01 năm 2018

Tóm tắt: Nghiên cứu tiến hành phân tích các mục tiêu phát triển Trung Quốc được thể hiện trong Báo cáo Chinh trị ${ }^{(l)}$ tại Đại hội lần thứ 19 Đảng Cộng sản Trung Quốc và tác động của các mục tiêu này đến chính sách đối ngoại của Trung Quốc đối với Việt Nam. Nghiên cứu chỉ ra rằng các mục tiêu này sẽ có cả tác động tích cực và tiêu cực đến chính sách đối ngoại của Trung Quốc đối với Việt Nam với chiều hướng và mức độ tùy thuộc vào nhận thức, mục tiêu và hành vi gia tăng quyền lực của Trung Quốc. Trong tình huống như vậy, quan hệ giữa Việt Nam và Trung Quốc sẽ phụ thuộc nhiều vào phản ứng của phía Việt Nam.

Tù khóa: quan hệ, Việt Nam, Trung Quốc, Đảng Cộng sản Trung Quốc, Đại hội lần thứ 19

\section{Đặt vấn đề}

Báo cáo Chính trị (tiếng Trung Quốc là 工作报告, dịch theo mặt chữ là Báo cáo công tác), còn được gọi là Diễn văn khai mạc (dưới đây gọi tắt là Báo cáo), do Tổng Bí thư Đảng Cộng sản Trung Quốc Tập Cận Bình trình bày tại phiên khai mạc Đại hội lần thứ 19, Đảng Cộng sản Trung Quốc, (18-24/10/2017) là văn kiện thu hút được sự quan tâm rộng rãi của cộng đồng quốc tế, đặc biệt là giới nghiên cứu quan hệ quốc tế. Ngoài phần đánh giá và tổng kết quá khứ, đánh giá thực trạng, hiện trạng trong và ngoài nước, Báo cáo còn đề ra những mục tiêu, định hướng và chính sách cho sự phát triển của Trung Quốc trong 5 năm tới và tương lai xa hơn. Những nhân tố này không chỉ ảnh hưởng đến mọi khía cạnh của đời sống xã hội

\footnotetext{
* ĐT.: 84-912093346

Email: ngocanh2us@vnu.edu.vn

${ }^{1}$ Nghiên cứu sử dụng toàn văn Báo cáo chính trị (工作 报告) bản tiếng Trung Quốc đăng tải trên website chính thức của Chính phủ Trung Quốc là Tân Hoa Xã (新华 社), truy cập tại địa chỉ: http://news.xinhuanet.com/ politics/19cpcnc/2017-10/27/c_1121867529.htm
}

Trung Quốc mà còn tác động rất lớn đến quan hệ giữa Trung Quốc với các quốc gia trên thế giới, trong đó có Việt Nam. Vì vậy, muốn hiểu rõ hơn mối quan hệ giữa Việt Nam và Trung Quốc trong 5 năm tới và tương lai xa hơn thì cần phải nghiên cứu những tác động có thể xảy ra của định hướng, chính sách, đặc biệt là chính sách đối ngoại, và mục tiêu được thể hiện trong Báo cáo đến quan hệ Trung Quốc - Việt Nam. Giới hạn trong khuôn khổ một bài viết, trên cơ sở tham chiếu lí thuyết quan hệ quốc tế và phân tích chính sách đối ngoại, nghiên cứu này chỉ tập trung xem xét những tác động có khả năng xảy ra của mục tiêu phát triển Trung Quốc được thể hiện trong Báo cáo đến chính sách đối ngoại của Trung Quốc đối với Việt Nam.

\section{Mục tiêu phát triển Trung Quốc trong Báo cáo}

Đại hội lần thứ 19 Đảng Cộng sản Trung Quốc

Như thường lệ 5 năm một lần, vào $9 \mathrm{~h}$ sáng ngày 18/10/2017, Đại hội đại biểu toàn 
quốc lần thứ 19 Đảng Cộng sản Trung Quốc đã chính thức khai mạc tại Đại lễ đường nhân dân ở thủ đô Bắc Kinh, Trung Quốc. Đại hội là sự chuyển giao quyền lực và công bố kế hoạch phát triển đất nước Trung Quốc trong 5 năm tiếp theo và tương lai xa hơn. Đại hội diễn ra trong bối cảnh trong nước Trung Quốc và quốc tế có một số điểm đáng chú ý như: ở trong nước, kinh tế Trung Quốc đang gặp phải những khó khăn và tăng trưởng chậm lại (Bloomberg, 2017), chiến dịch chống tham nhũng Đả hổ, diệt ruồi đã đạt được những kết quả đáng ghi nhận nhưng cũng đang gặp phải "khó khăn tầm thế giới" (world class hard) và sẽ chưa có hồi kết (Reuters, 2017), tiến trình tập trung quyền lực đạt được những thành công nhưng cũng đã gây ra sự chia rẽ trong đội ngũ lãnh đạo cao cấp trong Đảng Cộng sản Trung Quốc (Katsuji Nakazawa, 2016), thời hạn hoàn thành mục tiêu xã hội khá giả toàn diện vào năm 2020 được đề ra từ những kỳ đại hội trước đang đến rất gần, các biện pháp hiện thực hóa Giấc mo Trung Hoa - Công cuộc phuc hung đang được tăng cường tuyên truyền và đẩy mạnh thực hiện, chủ nghĩa dân tộc về một cường quốc hàng đầu thế giới tăng cao... Trên thế giới, chủ nghĩa dân tộc biệt lập, thương mại bảo hộ, xung đột dân tộc, sắc tộc có xu hướng gia tăng, căng thẳng trong quan hệ giữa Mỹ-Triều Tiên, Iran-Israel, NgaNATO... diễn biến phức tạp, tiềm ẩn nguy cơ xung đột vũ trang toàn cầu. Tuy nhiên, điểm sáng trong bức tranh toàn cầu là kinh tế thế giới tăng trưởng ổn định (World Bank, 2017), vị thế của Trung Quốc trên toàn cầu đã được nâng lên. Từ một số điểm đáng chú ý này có thể thấy Trung Quốc đang đứng trước cả những cơ hội và thách thức rất lớn để hoàn thành mục tiêu cuối cùng là hiện thực hóa Giấc mo Trung Hoa - Công cuộc phục hung, trở thành trung tâm vũ trụ.

Nội hàm các mục tiêu

Báo cáo do Tổng Bí thư Đảng Cộng sản Trung Quốc Tập Cận Bình trình bày tại phiên khai mạc Đại hội lần thứ 19 là văn kiện quan trọng nhất bởi vì Báo cáo chứa đựng những quyết sách quyết định tương lai Trung Quốc trong ít nhất là 5 năm tới và tương lai xa hơn. Theo thông tin trên website của Bộ Quốc phòng Trung Quốc(2) thì Báo cáo có độ dài hơn 30 nghìn chữ và được trình bày trong 3 tiếng 24 phút (9h07-12h31 theo giờ Bắc Kinh, 8h07-11h31 theo giờ Việt Nam). Cấu trúc nội dung chính của Báo cáo gồm 3 phần: đánh giá và tổng kết quá khứ; phân tích và đánh giá thực trạng, hiện trạng của Trung Quốc và thế giới; đưa ra định hướng, mục tiêu, chiến lược và chính sách cho giai đoạn tiếp theo. Nếu lấy thời điểm tổ chức Đại hội làm mốc thì có thể chia mục tiêu phát triển đất nước Trung Quốc được trình bày trong Báo cáo thành 3 loại: mục tiêu ngắn hạn (xã hội khá giả toàn diện vào năm 2020), mục tiêu trung hạn (xã hội chủ nghĩa hiện đại vào năm 2035) và mục tiêu dài hạn (cuờng quốc xã hội chủ nghĩa vào năm 2049). Các mục tiêu trong Báo cáo thể hiện chiến lược phát triển theo bậc thang, mục tiêu trước làm cơ sở cho mục tiêu sau, để thực hiện được muc tiêu sau phải hoàn thành mục tiêu trước. Vì vậy, xã hội khá giả toàn diện là mục tiêu đầu tiên Trung Quốc phải hoàn thành sau Đại hội 19. Xã hội khá giả toàn diện là một khái niệm dùng để chỉ xã hội trong đó các điều kiện cả về vật chất và tinh thần của toàn dân được đảm bảo ở mức độ khá. Do mức độ khá mang tính chủ quan, khó lượng hóa chi tiết nên các tiêu chí chi tiết chính thức của $x a ̃$ họi khá giả không được xác định rõ ràng và thường được điều chỉnh nội hàm qua các kì Đại hội Đảng Cộng sản Trung Quốc kể từ khi Đặng Tiểu Bình đề xuất chiến lược phát triển này vào cuối những năm 70 và đầu những năm 80 thế kỉ 20 (李彦增, 2008). Xã hội khá giả toàn diện là phiên bản đã được bổ sung của xã hội khá giả, bao gồm 5 lĩnh vực chính cần đạt được mức khá là kinh tế, chính trị, văn

\footnotetext{
${ }^{2} \mathrm{http} / / / \mathrm{www} .81 . \mathrm{cn} / \mathrm{dblj} / 2017-10 / 18 /$ content_77937432. $\mathrm{htm}$
} 
hóa, sinh thái và xã hội. Mục tiêu xã hội chủ nghĩa hiện đại vào năm 2035 còn mơ hồ hơn xã hội khá giả toàn diện. Báo cáo chủ yếu sử dụng các từ ngữ chỉ mức độ mang tính ước lượng như co bản, nhảy vọt, tầm cao mới, rõ rệt, sâu rộng, vĩng chắc, tràn đầy, căn bản... để nói về kết quả của 15 năm công cuộc hiện đại hóa chủ nghĩa xã hội - xã hội chủ nghĩa hiện đại vào năm 2035. Tuy nhiên, có thể xác định rõ ràng, xã hội chủ nghĩa hiện đại là giai đoạn phát triển tiếp theo và cao hơn của $x \tilde{a}$ họi khá giả toàn diện. Mục tiêu cuối cùng là cuoòng quốc xã hội chủ nghĩa, theo giải thích tại mục IV của Báo cáo về cuờng quốc xã họi chủ nghĩa là "đất nước dẫn đầu về sức mạn tổng hợp quốc gia và tầm ảnh huởng quốc tế, cơ bản thưc hiện toàn dân cùng giàu có, nhân dân Trung Quốc sẽ được huởng cuộc sống an khang hạnh phúc hơn, dân tộc Trung Hoa sẽ đứng sùng sũng giữa các dân tộc trên thế giới với tu thế hiên ngang hơ" thì cường quốc xã họi chủ nghĩa chính là mục đích và kết quả của Giấc mo Trung Hoa - Công cuộc phuc hung: trung tâm vũ trụ, siêu cường số một thế giới.

Quan hệ giũa mục tiêu và chính sách đối ngoại của Trung Quốc

Các mục tiêu trong Báo cáo thực chất là sự khái quát hóa và phản ánh những lợi ích quốc gia chủ chốt của Trung Quốc trong giai đoạn 2017-2049 như thịnh vượng, an ninh, quyền lực. Khi hoàn thành các mục tiêu này cũng có nghĩa là những lợi ích quốc gia chủ chốt của Trung Quốc được hiện thực hóa: Trung Quốc giàu có, an ninh được đảm bảo nhất, quyền lực lớn nhất thế giới.

Đã có rất nhiều nghiên cứu về mối quan hệ giữa lợi ích quốc gia và chính sách đối ngoại. Waltz (1979) cho rằng các quốc gia đều phải hoạch định các phương sách hành động mà các quốc gia này cho rằng phục vụ tốt nhất cho lợi ích của mình. Theo Morgenthau (1985), lãnh đạo quốc gia có nghĩa vụ hoạch định các chiến lược đối ngoại dựa trên phương châm chỉ đạo đã được xác định bởi lợi ích quốc gia. Gibosn Huge (1994) cũng cho rằng chính sách đối ngoại là nhằm mục đích tăng cường và bảo vệ lợi ích quốc gia. Chủ nghĩa Mác-Lênin cho rằng lợi ích quốc gia và ý chí của giai cấp thống trị chi phối chính sách đối ngoại và chính sách đối nội quyết định chính sách đối ngoại. Ở Trung Quốc "Đặng Tiểu Bình là nhà lãnh đạo đầu tiên xác định lợi ich quốc gia là xuất phát điểm của ngoại giao Trung Quốc” (孙建社, 2006). Từ các nghiên cứu này có thể thấy chính sách đối ngoại của Trung Quốc nói chung, đối với Việt Nam nói riêng, sẽ bị tác động bởi các mục tiêu trong Báo cáo. Để đánh giá tác động này thì nhất thiết phải thông qua các giải pháp được đưa ra để hiện thực hóa các mục tiêu. Các giải pháp chính được đề cập đến trong Báo cáo gồm:

(1) Phát triển hệ thống lí luận Chủ nghĩa Xã hội phù hợp với điều kiện thực tế của Trung Quốc ("Chủ nghĩa Xã hội đặc sắc Trung Quốc”) và tăng cường quyền lực của Đảng Cộng sản ("Đảng, chính, dân, học sinh, các miền Nam Bắc Tây Đông đều do Đảng lãnh đạo").

(2) Nâng cao tiềm lực kinh tế thông qua cải cách sâu rộng, đẩy mạnh công nghiệp chế tạo ("cuờng quốc chế tạo") và tăng cường thương mại và giao thương quốc tế ("cường quốc thương maii”).

(3) Gia tăng sức mạnh quân sự ("quân đội hàng đầu thế giới”) thông qua cải cách và hiện đại hóa.

(4) Xây dựng chế độ quản lí đất nước bằng pháp luật ("nhà nuoớc pháp quyền Xã hội chủ nghĩa").

(5) Gia tăng quyền lực toàn cầu ("quốc gia dẫn đầu về tầm ảnh huởng quốc tế") thông qua thúc đẩy quan hệ đối ngoại, tích cực tham gia các hoạt động quản trị toàn cầu, tăng cường quyền lực mềm thông qua truyền bá văn hóa và các giá trị Trung Quốc.

Những mục tiêu và giải pháp thực hiện sẽ khiến cho chính sách đối ngoại của Trung 
Quốc đối với Việt Nam diễn ra theo cả chiều hướng tích cực và tiêu cực. Tuy nhiên chiều hướng và mức độ của tác động sẽ như thế nào thì còn tùy thuộc vào quan điểm của giới tinh hoa và tình hình cụ thể trong nước Trung Quốc cũng như bối cảnh quốc tế tại những thời điểm nhất định. Dưới đây là phần phân tích chi tiết các chiều hướng và mức độ có khả năng sẽ xảy ra.

\section{Chiều hướng tích cực}

Tăng cuờng quan hệ với Việt Nam để củng cố, phát triển và hoàn thiện thể chế chinh trị

Không khó nhận thấy 3 mục tiêu trong Báo cáo chính là quá trình củng cố, phát triển và hoàn thiện thể chế chính trị và đó cũng là nhiệm vụ quan trọng số một tại các kỳ đại hội của Đảng Cộng sản Trung Quốc. Kể từ khi thành lập nước năm 1949 và trải qua 5 thế hệ lãnh đạo, thể chế chính trị Trung Quốc không ngừng được củng cố và phát triển. Trung Quốc luôn theo đuổi một thể chế chính trị phù hợp với điều kiện của mình đó là chế độ Xã hội chủ nghĩa phiên bản Trung Quốc và được gọi là Chủ nghĩa xã hội đặc sắc Trung Quốc. Từ tư tưởng Mao Trạch Đông, lí luận Đặng Tiểu Bình, học thuyết Giang Trạch Dân, quan điểm Hồ Cẩm Đào và gần đây nhất là tư tưởng Tập Cận Bình đều là những sự điều chỉnh thể chế chính trị Xã hội chủ nghĩa để một mặt "loại bỏ mọi nhân tố làm tổn hại đến tính tiên tiến và tính trong sạch của Đảng... bảo đảm Đảng Cộng sản Trung Quốc mãi mãi tràn đầy sức sống và sức chiến đấu"- tức củng cố và phát triển thể chế nhằm đáp ứng nhu cầu và sự thay đổi trong nước do sự phát triển của nền kinh tế, sự gia tăng hội nhập quốc tế và sự nâng cao trong nhận thức của toàn xã hội mang lại trong những giai đoạn nhất định, như trong Báo cáo gọi là "nỗi lo về dân sinh", "phát triển không cân bằng, không đầy đư”..., mặt khác nhằm thích ứng với bối cảnh quốc tế và chống lại những sự tấn công từ bên ngoài (hai trong "ba ngọn núi lớn"). Sau khi thực hiện công cuộc cải cách mở cửa cuối thập niên 70 thế kỉ 20 và đặc biệt là sau khi hệ thống Xã hội chủ nghĩa ở Liên Xô và Đông Âu sụp đổ vào những năm 90 thế kỉ 20, chế độ Xã hội chủ nghĩa và quyền lực của Đảng Cộng sản Trung Quốc đã và đang phải đối mặt với các nguy cơ cả ở trong nước và hệ thống quốc tế, như mục II của Báo cáo đã chỉ ra là "ngôn luận và hành vi làm suy yếu, bóp méo, phủ định sư lãnh đạo của Đảng và chế độ Xã hội chủ nghĩa ở Trung Quốc”. Xét từ góc độ thể chế chính trị, 3 mục tiêu trong Báo cáo đã xác định mục tiêu ngắn hạn là ổn định và củng cố thể chế chính trị, mục tiêu trung hạn là hiện đại và phát triển thể chế chính trị và mục tiêu dài hạn là hoàn thiện thể chế chính trị (cường quốc Xã hội chủ nghĩa đặc sắc Trung Quốc). Để hoàn thành các mục tiêu trong Báo cáo, Trung Quốc sẽ phải tiến hành song song hai hoạt động là phát triển hệ thống lí luận Chủ nghĩa Xã hội và gia tăng quyền lực của Đảng Cộng sản. Các thế hệ lãnh đạo Trung Quốc đã và đang không ngừng củng cố và phát triển các tư tưởng, học thuyết và lí luận của riêng mình đồng thời không ngừng củng cố quyền lực của Đảng Cộng sản. Trong quá trình này, Trung Quốc rất cần sự ủng hộ từ các quốc gia khác, đặc biệt là các quốc gia tương đồng về thể chế, cần có những đối tác để trao đổi, thảo luận, học hỏi, phản biện và sự ủng hộ đối với sự cầm quyền của Đảng Cộng sản Trung Quốc ở trong nước và trên trường quốc tế vì các nước có cùng thể chế có xu hướng ủng hộ, trọ giúp lẫn nhau (Hoàng Khắc Nam, 2011). Theo chủ nghĩa Mác-Lênin, chính sách đối ngoại bị quyết định bởi chính sách đối nội nên cũng mang tính giai cấp và bị chi phối bởi đấu tranh giai cấp. Việt Nam là quốc gia theo chế độ Xã hội chủ nghĩa nên có sự tương đồng với Trung Quốc về lí tưởng và giai cấp, vì vậy được xem là đồng minh của Trung Quốc. Ý nghĩa này được thể hiện trong lời nói của Tổng Bí thư Đảng Cộng sản Trung Quốc Tập Cận Bình tại Việt Nam năm 2015 là Việt Nam và Trung 
Quốc "có nhiều điểm tương đồng về lý tưởng và vận mệnh tương quan” (Nhân Dân, 2015), hay Hoàn Cầu Thời báo (白云怡、白天天, 2017) nói về chuyến thăm của Tổng Bí thư Đảng Cộng sản Trung Quốc Tập Cận Bình tại Việt Nam từ 12-13/11/2017 là "Trung-Việt tiền đồ tuơng quan, cùng chung vận mệnh". Ngoài ra, xét trên các phương diện chính như sức mạnh quốc gia, kinh nghiệm, tầm ảnh hưởng quốc tế, địa chính trị và mối tương quan chính trị giữa hai quốc gia thì Việt Nam là đối tác quan trọng số một trong quá trình hiện đại hóa và hoàn thiện Chủ nghĩa Xã hội của Trung Quốc. Vì vậy Đảng Cộng sản Trung Quốc sẽ phải đưa ra các biện pháp với các hình thức và cấp độ khác nhau nhằm tăng cường sự đoàn kết với Đảng Cộng sản Việt Nam, trong đó chú trọng tăng cường hợp tác về lĩnh vực lí luận. Chẳng hạn như tháng 5/2017, hai nước đã tổ chức hội thảo lí luận lần thứ 13 tại Trung Quốc (Hữu Hưng, 2017) và cuộc trao đổi lí luận giữa Học viện Chính trị quốc gia Hồ Chí Minh và Viện Khoa học Xã hội Trung Quốc tại Hà Nội vào ngày 13/11/2017 (Thông tin Đối ngoại, 2017); tiến hành những chuyến thăm viếng cấp cao thường xuyên và đặc biệt là trước và sau những sự kiện quan trọng của Đảng Cộng sản Trung Quốc tới Việt Nam nhằm tranh thủ sự ủng hộ của Việt Nam đối với sự cầm quyền của Đảng Cộng sản Trung Quốc ở cả trong nước và trên trường quốc tế... Nói tóm lại tăng cường quan hệ với Việt Nam là một trong những biện pháp quan trọng để Trung Quốc củng cố và hoàn thiện thế chế chính trị của mình. Điều này sẽ có tác động tích cực đến quan hệ hai nước.

Tăng cuờng quan hệ với Việt Nam để phát triển kinh tế

Kinh tế vừa là thành tố của mục tiêu lại vừa là điều kiện để hoàn thành các mục tiêu. Trên cả thực tiễn và lí thuyết, yếu tố kinh tế đều đóng vai trò quan trọng số 1 đối với việc hoàn thành bất cứ mục tiêu nào trong 3 mục tiêu đã đề ra. Vì vậy trong Báo cáo, vai trò của kinh tế được nâng lên tầm quan trọng đặc biệt và được xếp vào vị trí số 1 trong các thành tựu giai đoạn 2012-2017. Để trở thành trung tâm vũ trụ và đất nước dẫn đầu về súc mạn tổng hợp quốc gia và tầm ảnh hưởng quốc tế thì Trung Quốc phải có nền kinh tế tương ứng, trong đó tổng sản phẩm quốc nội và thu nhập bình quân đầu người là hai yếu tố luôn được toàn thể người Trung Quốc quan tâm theo dõi và kỳ vọng. Nhìn vào giải pháp số 2 là tăng cường chế tạo và đẩy mạnh hoạt động ngoại thương, có thể thấy xuất khẩu vẫn đóng vai trò quan trọng trong phát triển kinh tế của Trung Quốc. Sau hàng thập kỉ tăng trưởng hai con số nhờ có sự đóng góp quan trọng của xuất khẩu, trong vài năm trở lại đây kinh tế Trung Quốc rơi vào tình trạng giảm tốc, đã xuất hiện những dự báo và ý kiến cho rằng "nền kinh tế Trung Quốc ha cánh cứng là không thể tránh khỏi" (Reuters, 2016). Kinh tế suy giảm sẽ dẫn đến bất ổn xã hội, không chỉ ảnh hưởng xấu đến 3 mục tiêu mà còn đe dọa sự tồn vong của chế độ Xã hội Chủ nghĩa và quyền lực của Đảng Cộng sản Trung Quốc vì "tính chính danh của chế độ chủ yếu đến tù̀ thành công trong cải cách kinh tế" (Jamil Anderlini, 2013). Vì vậy "chắc chắn, chính sách đối ngoại của Trung Quốc sẽ tiếp tục được định hình chủ yếu bởi nhũng muc tiêu phát triển kinh tế trong nước" (Alice Ekman, 2017). Nền kinh tế Trung Quốc chủ yếu phụ thuộc vào xuất khẩu; để hoàn thành 3 mục tiêu, Trung Quốc hiện đang thực hiện những chiến lược kết nối kinh tế khu vực và toàn cầu như Hiệp định RCEP, Một vành đai-Một con đuờng... trong bối cảnh Chủ nghĩa Trọng thương có xu hướng gia tăng, đặc biệt là tại Mỹ, thì Trung Quốc sẽ phải chú trọng hơn đến quan hệ kinh tế với các quốc gia khác, trong đó có Việt Nam. Theo Bộ Công thương Việt $\mathrm{Nam}^{(3)}$ thì Việt Nam đã trở thành đối tác thương mại đứng đầu trong các nước ASEAN và là đối tác lớn thứ 8 của Trung

\footnotetext{
3 http://baocongthuong.com.vn/thuong-mai-viet-namtrung-quoc-ky-vong-muc-tieu-100-ty-usd.html
} 
Quốc trên toàn thế giới. Kim ngạch thương mại hai nước năm 2016 đạt 98,2 tỷ USD và năm 2017 dự kiến là 100 tỷ USD. Tuy nhiên có ý kiến cho rằng con số thực còn cao hơn do tình trạng buôn lậu khó kiểm soát ${ }^{(4)}$. Điều đáng chú ý và dễ nhận thấy là dù trong 5 năm trở lại đây kinh tế Trung Quốc giảm tốc nhưng kim ngạch thương mại giữa Trung Quốc và Việt Nam vẫn tăng đều qua các năm và điều này cho thấy vai trò của Việt Nam đối với sự phát triển kinh tế của Trung Quốc sẽ ngày một tăng. Từ những phân tích này có thể dự đoán Trung Quốc sẽ phải chú trọng đến bài toán kinh tế trong xử lí mối quan hệ với Việt Nam theo hướng tích cực để khai thác tiềm năng còn rất lớn trong mối quan hệ kinh tế với Việt Nam, đặc biệt là khi Việt Nam ngày càng hội nhập sâu rộng và tham gia vào nhiều tổ chức kinh tế lớn của khu vực và toàn cầu. Thương mại giữa hai nước phát triển sẽ có những tác động tích cực đến quan hệ hai nước.

Tăng cuờng quan hệ với Việt Nam để đảm bảo an ninh quốc gia

Một vành đai-Một con đường được xem là chiến lược chính nhằm hiện thực hóa cả 3 mục tiêu. Theo học giả Trung Quốc (陶林, 2017) khi thực hiện chiến lược này, Trung Quốc phải xử lí tốt mối quan hệ với các quốc gia láng giềng. Việt Nam có vị trí địa lí rất quan trọng đối với an ninh quốc gia của Trung Quốc. Việt Nam và Trung Quốc có chung đường biên giới dài $1449,566 \mathrm{~km}$, "trong đó đường biên giới trên đất liền là $1065,652 \mathrm{~km}$, đường biên giới nước là 383,914km" (Biên phòng Việt Nam, 2011). Hoàn Cầu Thời báo (吴乐珺, 2013) dẫn theo geopoliticalmonitor.com của Canada nhận định "vị trí địa lí đã khiến cho Việt Nam trở thành điểm khống chế tụ nhiên trên Biển Đông”, đồng thời dẫn lời học giả Trung Quốc Tô Hạo cho rằng "các nước ngoài khu vực nếu có quan hệ tốt với Việt Nam thi không nhũng

\footnotetext{
${ }^{4} \mathrm{https}$ ://www.gso.gov.vn/default.aspx?tabid=405\&idmi $\mathrm{d}=6 \&$ ItemID $=14349$
}

có thể hợp tác thuận lợi với ASEAN, mà còn có thể kiềm chế Trung Quốc. Đối với vấn đề Biển Đông, Việt Nam chiếm hũu nhiều đảo nhất, mâu thuẫn với Trung Quốc nhiều nhất, trong lịch sủ hai quốc gia không tin tuởng nhau, tùng xảy ra chiến tranh. Các nước phuoong Tây cảm thấy muốn kiềm chế Trung Quốc thì Việt Nam là quân bài hiệu quả nhất". Năm 2015, khi Tổng Bí thư Đảng Cộng sản Việt Nam sang thăm Mỹ, Nhân Dân Nhật báo và Hoàn Cầu Thời báo đã có phản ứng (Nguyễn Ngọc Anh, 2015). Qua những phân tích này, có thể thấy trong tư duy của Trung Quốc, tầm quan trọng của vị trí địa lí của Việt Nam nằm ở chỗ nó sẽ đe dọa nghiêm trọng an ninh quốc gia của Trung Quốc nếu Việt Nam hợp tác với các đối thủ của Trung Quốc, đặc biệt là Mỹ. Con đường To lụa trên biển và an ninh quốc gia của Trung Quốc sẽ bị đe dọa nghiêm trọng nếu như có bất ổn xảy ra giữa Việt Nam và Trung Quốc, đặc biệt là khi Việt Nam cho Mỹ thiết lập căn cứ quân sự trên lãnh thổ của Việt Nam và tiến hành các biện pháp phong tỏa trên Biển Đông. Khi đó, tương lai của mục tiêu cuối cùng của Trung Quốc là trở thành cường quốc số một thế giới sẽ trở nên khó đoán định. Trong lịch sử Trung Quốc, an ninh biên giới bất ổn, đặc biệt là xung đột biên giới, luôn có ảnh hưởng tiêu cực đến sự phát triển của Trung Quốc. Theo lí thuyết của Chủ nghĩa Tự do (Karen A Mingst, Ivan M Arreguin-Toft, 2014), hợp tác thông qua các cơ chế, định chế sẽ mang lại hiệu quả hơn là cạnh tranh hoặc đối đầu. Để có thể dồn tâm sức vào thực hiện các mục tiêu và giảm thiểu các lực cản từ bên ngoài, Trung Quốc sẽ thúc đẩy hơn nữa việc hợp tác an ninh với Việt Nam thông qua các cơ chế dưới các hình thức như hiệp định, thỏa thuận, biên bản ghi nhớ hợp tác,... vì khi đã tham gia vào các cơ chế các nước buộc phải coi trọng các nghĩa vụ mà họ đã kí (Helen V. Milner, 2009). Động thái này của Trung Quốc sẽ giúp đảm bảo an ninh ở của ngõ phía Nam không trở thành lực cản đối với việc hiện thực 
hóa các mục tiêu đã đề ra, đồng thời cũng giúp cho quan hệ Việt Nam-Trung Quốc diễn biến theo chiều hướng ổn định hơn.

Tăng cuờng quan hệ với Việt Nam để gia tăng quyền lục

Nhìn từ góc độ quan hệ quốc tế, 3 mục tiêu trong Báo cáo thể hiện một quá trình xây dựng và gia tăng quyền lực của Trung Quốc trong hệ thống quốc tế. Đầu tiên là nâng cao sức mạnh tổng hợp quốc gia bằng cách tăng cường các thành tố chủ chốt sản sinh ra quyền lực như chính trị, kinh tế, quân sự, khoa họccông nghệ... Tiếp theo, trên thành quả đạt được, Trung Quốc sẽ từng bước gia tăng quyền lực trên phạm vi toàn cầu, tức khả năng gây ảnh hưởng lên các quốc gia khác để đạt được những mục tiêu cho đến khi thay đổi được trật tự thế giới để trở thành trung tâm vũ trụ. Một bước ngoặt đáng chú ý là năm 2010, Trung Quốc trở thành nền kinh tế lớn thứ 2 thế giới thì năm 2013, Trung Quốc đã công khai mục tiêu cuối cùng là Giấc mo Trung Hoa-Công cuộc phuc hung, từ đó dẫn đến "chinh sách 'ẩn minh chò̀ thời' (蹈光养脢) nổi tiếng của Đặng Tiểu Bình gần nhu đã biến mất trong cẩm nang chinh sách đối ngoại của Trung Quốc" (Yun Sun, 2015). Trong quá trình xây dựng và gia tăng quyền lực trên phạm vi toàn cầu, Trung Quốc sẽ từng bước với các chiến lược và chiến thuật khác nhau xây dựng và gia tăng quyền lực tại các quốc gia với trọng tâm ưu tiên là các quốc gia láng giềng và lân cận trước, đặc biệt là tại các quốc gia không phải là đối thủ cạnh tranh vị thế quốc tế với Trung Quốc và có vị trí địa chính trị quan trọng như Việt Nam, Pakistan, Sri Lanka, Myanmar... - những quốc gia luôn nằm trong tầm ngắm và chịu ảnh hưởng của các đối thủ của Trung Quốc như Mỹ, Nga, Nhật Bản, Ân Độ hay Liên minh Châu Âu. Trong quá trình gia tăng quyền lực, Trung Quốc sẽ gặp phải nhiều trở lực khác nhau (Nguyễn Ngọc Anh, 2017), trong đó cuộc chiến quyền lực Mỹ-Trung là trở lực đáng chú ý nhất. Phần lớn các nghiên cứu đều tham chiếu lí thuyết của Chủ nghĩa Hiện thực và chỉ ra rằng Trung Quốc và Mỹ đang chơi trò chơi có tổng số bằng không, nghĩa là cái được của người này chính là cái mất của người kia, quyền lực của Trung Quốc tăng bao nhiêu cũng có nghĩa là quyền lực của Mỹ mất đi bấy nhiêu và ngược lại. Biểu hiện của cuộc chiến quyền lực này là sự tranh giành ảnh hưởng giữa Mỹ và Trung Quốc tại các quốc gia và tổ chức toàn cầu. Campuchia, Pakistan hay một số quốc gia Châu Phi đang được xem là những ví dụ điển hình. Chủ nghĩa Mác-Lênin cho rằng mâu thuẫn giai cấp chi phối quan hệ quốc tế, không cùng giai cấp sẽ không cùng lợi ích từ đó dẫn đến xung đột lợi ích và xung đột chủ yếu giữa hai giai cấp là vô sản và tư sản (Hoàng Khắc Nam, 2017). Việt Nam và Trung Quốc đều là nước Xã hội chủ nghĩa dưới sự lãnh đạo của giai cấp vô sản, nghĩa là cùng lợi ích; trong khi đó, các nước như Mỹ, Nhật Bản hay nhiều nước Châu Âu là quốc gia tư bản dưới sự lãnh đạo của giai cấp tư sản, đối lập lợi ích với Việt Nam và Trung Quốc. Dưới sự chỉ đạo của tư tưởng này, Trung Quốc sẽ khai thác triệt để những lợi thế ảnh hưởng vốn có của mình đối với Việt Nam trong các lĩnh vực chính trị, kinh tế, văn hóa, một mặt hạn chế tối đa các bất đồng và xung đột làm tổn hại mối quan hệ hai bên, mặt khác đẩy mạnh giao lưu, hợp tác trên các lĩnh vực trọng yếu ở các cấp độ khác nhau để thắt chặt quan hệ và gia tăng quyền lực tại Việt Nam. Trung Quốc nhiều khả năng sẽ muốn chứng tỏ cho Việt Nam thấy những lợi ích cả về chính trị và kinh tế khi hợp tác với đối tác đồng lí tưởng, đồng giai cấp.

\section{Chiều hướng tiêu cực}

Tăng cường sức ép để gia tăng quyền lực

Nếu xét theo quan điểm của Chủ nghĩa Hiện thưc, thì mục tiêu toàn cầu của Trung Quốc cần phải tỉ lệ thuận với quyền lực toàn cầu của Trung Quốc. Mục tiêu lớn cần phải có quyền lực lớn sẽ đồng nghĩa với việc Trung 
Quốc muốn hoàn thành Giấc mo Trung HoaCông cuộc phưc hưng để trở thành trung tâm vũ trụ thì cần phải có quyền lớn nhất trong hệ thống quốc tế, tức là quốc gia dẫn đầu về tầm ảnh huơơng quốc tế đã được đề cập trong Báo cáo. Trong quá trình gia tăng quyền lực, Trung Quốc sẽ gặp phải nhiều trở lực từ một số quốc gia như Nhật Bản, Ân Độ, Nga... trong đó đáng chú ý nhất là trở lực từ Mỹ. Việt Nam tuy là nước Xã hội chủ nghĩa nhưng do thực hiện phương châm đối ngoại làm bạn với tất cả các nước nên có quan hệ ngoại giao với các quốc gia gồm cả Xã hội chủ nghĩa và Tư bản chủ nghĩa, cả bạn và đối thủ của Trung Quốc. Điều đáng chú ý là Việt Nam đã thiết lập quan hệ đối tác chiến lược với 4 quốc gia được đánh giá là đối thủ hàng đầu trong cạnh tranh quyền lực với Trung Quốc là Nga, Ấn Độ, Nhật Bản và Mỹ. Trên lí thuyết, thời hạn thực hiện mục tiêu càng đến gần, Trung Quốc càng cần phải đẩy nhanh tốc độ gia tăng quyền lực, từ đó dẫn đến cục diện cạnh tranh quyền lực giữa Trung Quốc và các đối thủ sẽ ngày càng quyết liệt. Từ góc độ địa chính trị, Việt Nam sẽ là một trong số những quốc gia nằm trong sách ưu tiên gia tăng quyền lực của cả Trung Quốc và các đối thủ của Trung Quốc. Vì vậy Việt Nam sẽ nhận được sự quan tâm hơn nhưng cũng sẽ phải đối mặt với nhiều áp lực hơn từ Trung Quốc, nhất là khi Việt Nam kiên định chính sách ngoại giao "3 không" (không tham gia liên minh hay các tổ chức liên minh quân sự, không cho nước ngoài đặt căn cứ quân sự hoặc sử dụng lãnh thổ của mình để chống lại nước khác, không đi với nước này để chống nước kia ${ }^{(5)}$ ) và kiên trì thực hiện đường lối đối ngoại độc lập, tự chủ, rộng mở, đa dạng hoá, đa phương hoá quan hệ quốc tế, sẵn sàng là bạn và là đối tác tin cậy của tất cả các nước trong cộng đồng thế giới(i), từ

\footnotetext{
${ }^{5} \mathrm{https}: / /$ vnexpress.net/tin-tuc/the-gioi/tu-lieu/tuong-nguyenchi-vinh-tra-loi-phong-van-bao-nhat-2176370.html

${ }^{6}$ Tham khảo website Bộ Ngoại giao Việt Nam: http:// www.mofahcm.gov.vn/vi/mofa/cs_doingoai/cs/ ns040823163300
}

đó khiến cho Trung Quốc khó khăn trong việc gia tăng quyền lực. Sức ép của Trung Quốc đối với Việt Nam cũng sẽ tăng lên khi các đối thủ của Trung Quốc, đặc biệt là Mỹ hoặc Nhật Bản cũng tìm cách gia tăng quyền lực tại Việt Nam khiến cho Trung Quốc gặp khó khăn trong tiến trình thực hiện các mục tiêu. Cường độ sức ép của Trung Quốc đối với Việt Nam có lẽ sẽ phụ thuộc nhiều vào cán cân tương quan quyền lực giữa Trung Quốc với các đối thủ và phản ứng từ phía Việt Nam. Sức ép có thể sẽ khiến cho quan hệ Việt Nam-Trung Quốc xuất hiện những căng thẳng tại những thời điểm nhất định.

Gia tăng áp lục trong tranh chấp biển đảo với Việt Nam

Để hiểu được trong quá trình thực hiện các mục tiêu tại sao Trung Quốc sẽ gia tăng áp lực trong tranh chấp biển đảo với Việt Nam thì trước tiên cần phải tìm hiểu tầm quan trọng của Biển Đông đối với các mục tiêu đó. Khi sức mạnh tổng hợp quốc gia và ảnh hưởng toàn cầu tăng lên sẽ đồng nghĩa với việc Trung Quốc sẽ có quyền lực lớn hơn, vì vậy Trung Quốc sẽ quyết đoán hơn với những gì được xem là lợi ích quốc gia. Biển Đông sẽ là nơi để Trung Quốc thể hiện quyền lực của mình. Theo Walter Lohma (2017), Giám đốc Trung tâm Nghiên cứu châu Á thuộc Quỹ Heritage, hai lợi ích quan trọng nhất đối với Trung Quốc ở Biển Đông là an ninh và kinh tế. Về an ninh, nếu kiểm soát được Biển Đông, Trung Quốc ngoài việc có được bức tường bảo vệ chống xâm nhập và tiếp cận từ biển, còn phá vỡ được vòng vây và có tác dụng răn đe đối với Mỹ và các đồng minh. Về kinh tế, thương mại chiếm khoảng $40 \%$ GDP của Trung Quốc, với phần lớn đến từ biển, Biển Đông là ngư trường và được dự báo có trữ lượng tài nguyên năng lượng rất lớn. Robert D. Kaplan (2015) cho rằng Biển Đông kết nối Ân Độ Dương và Thái Bình Dương với các tuyến đường thương mại và tuyến thông tin liên lạc trọng yếu, vì vậy nếu kiểm soát được Biển Đông, Trung Quốc sẽ có khả năng thay đổi cán cân quyền lực 
ở Đông bán cầu. Điểm đáng chú ý là Trung Quốc đã xác định vai trò của biển đối với việc thực hiện các mục tiêu là "biển quan hệ đến sụ thịnh suy, an nguy của đất nước... kiên định tiến ra biển và xây dựng cường quốc biển có ýnghĩa to lớn và sâu sắc đối với việc thúc đẩy sư phát triển lành mạnh của kinh tếxã hội đất nuớc, bảo vệ các lợi ich chủ quyền, an ninh và phát triển, thực hiện muc tiêu xã hội khá giả toàn diện tiến tới hiện thực hóa công cuộc phuc hung vĩ đại dân tộc Trung Hoa. Nhìn lại lịch sử, tiến ra biển là con đường tất yếu chấn hung dân tộc, xây dựng đất nước giàu mạnh.” (王宏, 2017). Trung Quốc đã tuyên bố chủ quyền với khoảng $80 \%$ diện tích Biển Đông, tuy nhiên điều này không có nghĩa là Trung Quốc sẽ phải bằng mọi giá thôn tính cho bằng được gần như toàn bộ Biển Đông trên thực địa. Thay vào đó Trung Quốc sẽ chỉ cần xây dựng được năng lực kiểm soát Biển Đông, sau đó áp đặt các luật chơi và buộc các nước khác phải tuân thủ. Dù Trung Quốc thôn tính trên thực địa hay kiểm soát và áp đặt luật chơi thì các nước có tranh chấp với Trung Quốc đều sẽ có những phản kháng quyết liệt. Xuất phất từ nhận định về vai trò của Biển Đông đối với việc hiện thực hóa các mục tiêu trong Báo cáo, Trung Quốc có thể sẽ lựa chọn thời điểm thích hợp với các chiến thuật khác nhau để gia tăng áp lực đối với các nước có liên quan. Theo nhận định của học giả Trung Quốc (刘峻凌, 2012) trong tranh chấp Biển Đông thì Việt Nam là quốc gia có tranh chấp với Trung Quốc nhiều nhất. Việt Nam lại là quốc gia cửa ngõ trên con đường Nam tiến của Trung Quốc trên Biển Đông, vì vậy khi thực hiện các mục tiêu, Trung Quốc sẽ không loại trừ khả năng sẽ gia tăng áp lực lên Việt Nam trong vấn đề Biển Đông. Từ sau khi Việt Nam và Trung Quốc bình thường hóa quan hệ vào năm 1991, tranh chấp Biển Đông giống như một một chiếc "vô-lăng" có thể lái cỗ xe quan hệ hai nước rẽ theo chiều hướng tích cực hoặc tiêu cực.
Gia tăng sự lệ thuộc của Việt Nam vào Trung Quốc

Động thái tăng cường quan hệ với Việt Nam của Trung Quốc một mặt sẽ giúp cho quan hệ hai nước phát triển và ổn định hơn, mặt khác có thể sẽ làm gia tăng nguy cơ Việt Nam bị lệ thuộc vào Trung Quốc, đặc biệt là về kinh tế và chính trị vì "Trung Quốc muốn Việt Nam phát triển tốt nhưng phải ở trong vòng cương tỏa của Trung Quốc" (Vũ Cao Phan, 2017).

Về chính trị, để thích ứng với điều kiện mới trong nước và quốc tế, Việt Nam cũng sẽ cần phải có những điều chỉnh về thể chế chính trị. Theo Chủ nghĩa Mác-Lênin thì cùng giai cấp sẽ cùng lợi ích và hợp tác, giai cấp vô sản thế giới cần đoàn kết lại để tiến hành cách mạng và lật đổ sự thống trị của giai cấp tư sản. Việt Nam và Trung Quốc có sự tương đồng về thể chế chính trị, đều là hai nước Xã hội chủ nghĩa, cùng giai cấp, "có nhiều điểm tuoong đồng về lý tuởng và vận mệnh tuoong quan”, vì vậy Trung Quốc sẽ tăng cường hoạt động giao lưu, hợp tác để gây ảnh hưởng về chính trị đối với Việt Nam. Trong quá trình này, ý thức hệ và thành công về chính trị của Trung Quốc có thể sẽ có những ảnh hưởng nhất định đến Việt Nam.

Về mặt kinh tế, đã có nghiên cứu chỉ ra rằng nhập khẩu của Việt Nam lệ thuộc vào Trung Quốc: "Việt Nam đang giữ vị trí cao nhất trong số các đối tác lớn như Mỹ, châu Âu, Nhật Bản và khu vực Đông Nam Á (ASEAN) về mức độ phụ thuộc nhập khẩu từ Trung Quốc" (Phương Linh, 2015). Trong thời gian sắp tới, khi Trung Quốc đẩy mạnh giải pháp kinh tế để hiện thực hóa các mục tiêu như trong Báo cáo đã đề ra là tăng cường chế tạo và xuất khẩu thông qua các kết nối kinh tế với Việt Nam hoặc có sự tham gia của Việt Nam thì nguy cơ lệ thuộc của Việt Nam vào hàng hóa Trung Quốc sẽ gia tăng. Bên cạnh đó, để tìm kiếm lợi ích kinh tế và gia tăng quyền lực ở bên ngoài lãnh thổ, Trung Quốc sẽ thông qua các chiến lược với trọng tâm là Một vành đai- 
Một con đường để tăng cường rót vốn vào các nước đang phát triển trong đó có Việt Nam. Brahma Chellaney (2017) cho rằng "Trung Quốc đang hỗ trợ xây dựng các dự án cơ sở hạ tầng ở các nước đang phát triển nằm ở các vị trí chiến lược, thường là bằng cách cung cấp các khoản vay khổng lồ cho chính phủ các nước này. Từ đó, các nước ngày càng sa vào bẫy nợ khiến họ trở nên dễ bị chi phối trước ảnh hưởng của Trung Quốc". Việt Nam hiện đang cần nguồn vốn lớn để phát triển, những khoản cho vay "có mục tiêu chiến lược" của Trung Quốc có khả năng sẽ làm gia tăng nguy cơ lệ thuộc của Việt Nam vào Trung Quốc.

Gây căng thẳng hoặc tạo xung đột với Việt Nam để đánh lạc hướng du luận trong nước

Ernst B. Haas và Allen S. Whiting (1956) nhận định giới tinh hoa có thể bị chi phối bởi chính sách xung đột quốc tế, nếu không muốn nói là chiến tranh, để bảo vệ mình trước sự tấn công của đối thủ trong nước, thậm chí Simmel (dẫn theo Jack S. Levy, 1989) còn cho rằng chiến tranh với bên ngoài đôi khi là cơ hội cuối cùng cho quốc gia bị đè nặng bởi mâu thuẫn nội bộ phải vượt qua được những mâu thuẫn ây, nếu không, quốc gia đó chắc chắn sẽ bị đổ vỡ. Một trong những lí do quan trọng khiến Trung Quốc phát động Chiến tranh Biên giới năm 1979 đối với Việt Nam là chuyển hướng sự chú ý của dư luận trong nước (BBC, 2017). Học giả J. Michael Cole (2014) cho rằng khi phải đối mặt với áp lực trong nước, Chính phủ Trung Quốc thường xuyên sử dụng giải pháp gây hấn với nước khác để đánh lạc hướng và chuyển áp lực ra bên ngoài. Trong tương lai nếu cần phải lựa chọn giải pháp này thì địa điểm đầu tiên được lựa chọn để gây hấn sẽ là Biển Đông vì sẽ dễ dàng khai thác được chủ nghĩa dân tộc và các bên tranh chấp đều yếu hơn so với Trung Quốc. Patrik Meyer (2016) nhận định từ năm 2012 trở lại đây, Trung Quốc chọn giải pháp cứng rắn trong tranh chấp Biển Đông có thể là để chuyển hướng sự chú ý của người dân nước này ra khỏi các vấn đề căng thẳng trong nước và để có điều kiện giải quyết các vấn đề trong nước.

Từ những phân tích này có thể dự đoán trong quá trình thực hiện các mục tiêu, nếu xuất hiện các diễn biến bất lợi có xu hướng làm gia tăng sự bất ổn xã hội hoặc mẫu thuẫn trong tầng lớp tinh hoa chính trị dẫn đến nguy cơ khiến cho Trung Quốc không những không thể hoàn thành được các mục tiêu mà còn suy yếu đi thì giới tinh hoa Trung Quốc chắc chắn sẽ phải tìm biện pháp củng cố nội bộ và chuyển hướng chú ý của dư luận trong nước và quốc tế vào vấn đề khác. Trong tình huống như vậy, có thể sẽ không hoàn toàn loại trừ khả năng Trung Quốc sẽ tạo căng thẳng hoặc gây xung đột với nước khác và Biển Đông sẽ có khả năng là sự lựa chọn đầu tiên. Căng thẳng trong tranh chấp Biển Đông luôn khiến cho quan hệ Việt Nam-Trung Quốc xấu đi nhanh chóng.

\section{Kết luận}

Quá trình thực hiện các mục tiêu cũng chính là quá trình trỗi dậy, Trung Quốc có trỗi dậy một cách hòa bình hay không là câu hỏi đã bắt đầu được đặt ra cách đây nhiều năm trước. Theo John J. Mear Sheimer (2013) dù đã có nhiều nghiên cứu và tranh luận nhưng đây vẫn còn là câu hỏi mở (open question), nguyên nhân là do giới nghiên cứu chịu ảnh hưởng của hai trường phái khác nhau trong Chủ nghĩa Hiện thưc là trường phái tấn công và trường phái phòng thủ. Các nghiên cứu chịu ảnh hưởng của trường phái tấn công cho rằng Trung Quốc sẽ xưng bá ở Châu Á và áp dụng học thuyết Monroe ${ }^{(7)}$ phiên bản Trung Quốc, từ đó tạo nên sự đối đầu giữa một bên là Trung Quốc và bên kia là một liên minh kiềm chế sự trỗi dậy của Trung Quốc gồm Mỹ, đồng minh của Mỹ và

\footnotetext{
${ }^{7}$ Học thuyết Monroe là một chính sách của Mỹ được trình bày vào ngày 2 tháng 12 năm 1823 bởi Tổng thống Mỹ James Monroe trước Quốc hội. Mục đích là chống sự xâm nhập và ảnh hưởng của các cường quốc Châu Âu đối với các quốc gia Mỹ La-tin từ đó nhằm duy trì sự ảnh hưởng của Mỹ.
} 
các nước láng giềng lo ngại sự trỗi dậy của Trung Quốc. Trong khi đó các nghiên cứu chịu ảnh hưởng của trường phái phòng thủ thì lại cho rằng Trung Quốc tuy lớn mạnh nhưng sẽ tìm cách cân bằng quyền lực và không xưng bá vì vậy sẽ chung sống hòa bình với tất cả các nước láng giềng và Mỹ. Trung Quốc có trỗi dậy một cách hòa bình hay không có lẽ sẽ vẫn còn tiếp tục được tranh luận vì cho đến thời điểm hiện tại các nghiên cứu theo hai trường phái khác nhau đều đã đưa ra những lập luận và bằng chứng để chứng tỏ quan điểm của mình là đúng. Điều này cũng có nghĩa là tác động của các mục tiêu trong Báo cáo đến chính sách đối ngoại của Trung Quốc đối với Việt Nam sẽ vẫn còn tiếp tục được nghiên cứu tiếp. Tuy nhiên, để đánh giá một cách toàn diện tác động của các mục tiêu đến chính sách đối ngoại của Trung Quốc đối với Việt Nam thì ngoài việc tham khảo các nghiên cứu thuộc hai trường phái này, còn cần phải tham khảo một yếu tố thường được giới nghiên cứu sử dụng, đó là lịch sử quan hệ hai nước. Học giả Martin Jacques (2015) cho rằng trong hàng nghìn năm qua, hai bên đã có mối quan hệ với rất nhiều vấn đề, vì thế, tương lai sẽ là một phần tiếp diễn của lịch sử. Học giả Trung Quốc Xie Tao (2017) cũng cho rằng bài học quá khú có thể cho chúng ta biết gì về tuoong lai của mối quan hệ Việt-Trung có vẻ đúng. Nhìn lại lịch sử quan hệ giữa Việt Nam và Trung Quốc, quyền lực luôn là tâm điểm của mối quan hệ: căng thẳng, xung đột hay hữu hảo đều phụ thuộc vào nhận thức, mục tiêu và hành vi gia tăng quyền lực của phía Trung Quốc và phản ứng của phía Việt Nam. Qua những phân tích ở trên, chúng ta có thể thấy chính sách đối ngoại của Trung Quốc đối với Việt Nam sẽ diễn ra theo cả chiều hướng tích cực và tiêu cực và bị chi phối bởi nhận thức, mục tiêu và hành vi gia tăng quyền lực của phía Trung Quốc. Trong tình huống như vậy, quan hệ Việt Nam và
Trung Quốc ra sao trong tương lai khi Trung Quốc thực hiện các mục tiêu sẽ phụ thuộc nhiều vào phản ứng của phía Việt Nam.

\section{Tài liệu tham khảo}

\section{Tiếng Việt}

Nguyễn Ngọc Anh (2015). Về nhận định của Nhân Dân Nhật báo và Hoàn Cầu Thời báo đối với chuyến thăm Mỹ của Tổng Bí thư Đảng Cộng sản Việt Nam. Nghiên cúu Nước ngoài, 31(3), 18-27.

Nguyễn Ngọc Anh (2017). Trở lực từ một số chủ thể trong hệ thống quốc tế trên con đường trở thành bá quyền của Trung Quốc. Nghiên cứu Nuớc ngoài, $33(5), 15-26$.

BBC (2017). Chiến tranh với Việt Nam 1979: Trung Quốc rút ra bài học gì? Truy cập lúc 9:30 ngày 20/12/2017 tại <http://www.bbc.com/vietnamese/ vietnam-39760652>

Biên phòng Việt Nam (2011). Biên giới đất liền Việt Nam - Trung Quốc. Truy cập lúc 11:30 ngày 8/12/2017 tại $<$ http://bienphongvietnam.vn/cong-tac-bien-phong/ duong-bien-moc-gioi/223-dbmg04.html>

Thanh Bình (2014). Thủ tuoóng: 'Không đánh đổi chủ quyền láy hưu nghị viển vông'. Truy cập lúc 14:17 ngày 19/12/2017 tại <https://vnexpress.net/tin-tuc/ the-gioi/thu-tuong-khong-danh-doi-chu-quyen-layhuu-nghi-vien-vong-2994075.html>

Hữu Hưng (2017). Khai mac trọng thể Hội thảo lý luận lần thứ 13 giũa Đảng Cộng sản Việt Nam và Đảng Cộng sản Trung Quốc. Truy cập lúc 13:15 ngày 18/12/2017 tại <http://www.nhandan.com.vn/ chinhtri/item/32969802-khai-mac-hoi-thao-ly-luanlan-thu-13-giua-dang-cong-san-viet-nam-va-dangcong-san-trung-quoc.html>

Phương Linh (2015). Việt Nam lệ thuộc hàng hóa Trung Quốc nhiều nhất Đông Nam Á. Truy cập lúc 15:25 ngày 15/1/2017 tại <https://kinhdoanh.vnexpress. net/tin-tuc/vi-mo/viet-nam-le-thuoc-hang-hoatrung-quoc-nhieu-nhat-dong-nam-a-3321752.html>

Hoàng Khắc Nam (2011). Quyền lực trong quan hệ quốc tế, lịch sử và vấn đề. Hà Nội: Nxb Văn hóa thông tin.

Hoàng Khắc Nam (2017). Lý thuyết quan hệ quốc tế. Hà Nội: Nxb Thế giới.

Thông tin Đối ngoại (2017). Việt Nam - Trung Quốc tăng cuờng trao đổi nghiên cứu lý luận chính trị. Truy cập lúc 15:25 ngày 14/12/2017 tại <http:// tapchithongtindoingoai.vn/ly-luan-thuc-tien-kinhnghiem/viet-nam-trung-quoc-tang-cuong-trao-doinghien-cuu-ly-luan-chinh-tri-13139>

Vũ Cao Phan (2017). Liệu ông Tập Cận Bình có nhiệm kỳ thú ba? Truy cập lúc 8:45 ngày 16/12/2017 tại <http://www.bbc.com/vietnamese/ world-39179635> 


\section{Tiếng Anh}

Anderlini, J. (2013). How long can the Communist party survive in China? Available through $<$ https:// www.ft.com/content/533a6374-1 fdc-11e3-886100144feab7de>, Accessed 10/12/2017 17:15.

Bloomberg (2017). China's Economy Cools Again. Available through <https://www.bloomberg. com/news/articles/2017-09-14/china-s-economycools-again-as-industry-retail-investment-slow $>$, Accessed 12/11/2017 17:15.

Chellaney, B. (2017). China's Debt-Trap Diplomacy. Project Syndicate. Available through < https://www. project-syndicate.org/commentary/china-one-beltone-road-loans-debt-by-brahma-chellaney-201701?barrier=accessreg $>$, Accessed 12/1/2018 14:20.

Cole, J. (2014). Where Would Beijing Use External Distractions? Available through < https:// thediplomat.com/2014/07/where-would-beijinguse-external-distractions/>, Accessed 15/12/2017 18:15.

Ekman, A. (2017). Foreign Policy: The Domestic Driver. Chinese futures: Horizon 2025, 35, 35-40.

Haas, E., \& Whiting, A.(1956). Dynamics of international relations. New York, NY: McGrawHill Book.

Huge, G. (1994). The Road to Foreign Policy. New York, NY: Doubleday, Doran and Company.

Milner, H. (2009). Power, Interdependence, and Nonstate Actors in World Politics: Research Frontiers. Princeton, NJ: Princeton University Press, pp. 3-27.

Jack, S. L. (1989). The Diversionary Theory of War, in Manus I. Midlarsky (ed.), Handbook of War Studies. Boston: Unwin Hyman.

Jacques, M. (2015). Beijing faces challenge of keeping up good governance. Available through < http://www. todayonline.com/world/beijing-faces-challengekeeping-good-governance-0 ? singlepage $=$ true $>$, Accessed 14/11/2017 17:15.

Kaplan, R. D. (2015). Asia's Cauldron: the South China Sea and the End of a Stable Asia - Pacific. New York, NY: Random House Trade Paperbacks.

Lohma, W. (2017). China hasn't won yet in the South China Sea. Available through < https://www. gisreportsonline.com/china-hasnt-won-yet-inthe-south-china-sea,defense,2234,report.html>, Accessed 7/12/2017 9:30,

Marleku, M. A. (2013). National Interest and Foreign Policy: The Case of Kosovo. Mediterranean Journal of Social Sciences, 4(3), 415-419.

Mearsheimer, J. (2013). Case study: can China rise peacefully, in Tim Dunne, Milja Kurki, Steve Smith (ed.), International Relations Theories Discipline and Diversity ( $3^{\text {th }}$ ed). Oxford: Oxford University.

Meyer, P. (2016). China's Non-Chinese Approach to the South China Sea. Available through < https:// thediplomat.com/2016/09/chinas-non-chineseapproach-to-the-south-china-sea/>, Accessed 12/12/2017 10:15.

Mingst, K. A. (2014). Essentials of International Relations. New York: W.W. Norton \& Company.

Morgenthau (1985). Politics Among Nations: The Struggle for Power and Peace $\left(6^{\text {th }}\right.$ ed). New York, NY: Knopf.

Nakazawa, K. (2016). Xi Jinping, Li Keqiang take political battle into economic arena. Available through $<$ https://asia.nikkei.com/Politics-Economy/ Policy-Politics/Xi-Jinping-Li-Keqiang-takepolitical-battle-into-economic-arena>, Accessed 14/11/2017 17:15.

Reuters (2017). China top graft buster says corruption fight, world class hard'. Available through $<$ https:// www.reuters.com/article/us-china-corruption/chinatop-graft-buster-says-corruption-fight-world-classhard-idUSKCN1BW098>, Accessed 12/11/2017 10:15.

Waltz (1979). Theory of International Politics. New York, NY: Mc-Graw-Hall.

World Bank (2017). Global Economic Prospects - June 2017 - Global Outlook. Available through < http:// pubdocs.worldbank.org/en/216941493655495719/ Global-Economic-Prospects-June-2017-GlobalOutlook.pdf>, Accessed 13/11/2017 9:30.

Xie Tao (2017). China and Vietnam: Thoughts From a Chinese Sojourner in Ho Chi Minh City. Available through $<$ https://thediplomat.com/2017/03/chinaand-vietnam-thoughts-from-a-chinese-sojourner-inho-chi-minh-city/>, Accessed 17/12/2017 15:30.

Yin Wei (2008). Public Diplomacy and the Rise of Chinese Soft Power. The Annals of the American Academy of Political and Social Science, 616, $257-$ 273.

Yun Sun (2015). China's Preferred World Order: What Does China Want? PacNet, No.62. Available through $<$ https://csis-prod.s3.amazonaws.com/s3fspublic/legacy_files/files/publication/Pac1562.pdf>, Accessed 11/12/2017 16:30.

\section{Tiếng Trung Quốc}

白云怡、白天天 (2017). 习近平双重身份访越南. 环 球时报. 北京: 人民日报社

鄧聿文 (2017). 對中國外交的九個反思. Available through $<$ http://big5.ftchinese.com/story/001073219?full=y>, Accessed 19/12/2017 20:15

李彦增 (2008). 全面建设小康社会. Available through <http://cpc.people.com.cn/GB/134999/135000/8103388.html>, Accessed 12/11/2017 20:15

刘峻凌 (2012). 点评南海争端诸国立场 越南与中 国争议最大. Available through < http://www.china.com.cn/ international/txt/2012-05/11/content_25359513.htm>, Accessed 12/12/2017 20:15

孙建社 (2006). 邓小平外交思想中的国家利 益观. Available through $<$ http://cpc.people.com.cn/ 
GB/69112/69113/69117/4714249.html>, Accessed 18/12/2017 9:15

陶林 (2017). “一带一路”战略实施必须处理好十大关

系. Available through <http://www.zaobao.com.sg/forum/views/ opinion/story20170807-785172>, Accessed 11/12/2017 9:15
王宏 (2017). 海洋强国建设助推实现中国梦. 人民日 报. 北京: 人民日报社

吴乐珺(2013). 越南是西方牵制中国的一张牌 与中

国矛盾最多. Available through $<$ http://mil.huanqiu.com/ paper/2013-10/4442773.html $>$, Accessed 7/12/2017 20:15

\title{
THE IMPACTS OF THE DEVELOPMENT TARGETS IN THE POLITICAL REPORT DELIVERED AT THE $19^{\text {th }}$ NATIONAL CONGRESS OF THE COMMUNIST PARTY OF CHINA ON FOREIGN POLICY TOWARDS VIETNAM
}

\author{
Nguyen Ngoc Anh \\ Center for Foreign Language Education Research, Linguistics and International Studies, \\ VNU University of Languages and International Studies, Pham Van Dong, Cau Giay, Hanoi, \\ Vietnam
}

\begin{abstract}
The article analyzes the Chinese national development targets in the Political Report delivered at the $19^{\text {th }}$ National Congress of the Communist Party of China and the impacts of these targets on China's foreign policy towards Vietnam. The author posits that the impacts of these targets on China's foreign policy towards Vietnam will be both positive and negative. The trend and degree of these impacts will be determined by China's awareness, goals and actions for increasing its power. In this situation, what the relationship between China and Vietnam will be like depends mostly on Vietnam's reactions.

Keywords: relationship, Vietnam, China, Communist Party, National Congress
\end{abstract}

